\title{
$11 \%$ EFFICIENCY ON CIGS SUPERSTRATE SOLAR CELLS WITHOUT SODIUM PRECURSOR
}

\author{
F.-J. Haug, H. Zogg, A. N. Tiwari \\ Swiss Federal Institute of Technology (ETH), Laboratory of Solid State Physics, \\ Thin Film Physics Group, Technoparkstrasse 1, CH-8005 Zurich, Switzerland, \\ Tel: +41 1445 1474, e-mail: tiwari@phys.ethz.ch
}

\begin{abstract}
$\mathrm{Cu}(\mathrm{In}, \mathrm{Ga}) \mathrm{Se}_{2}$ superstrate solar cells were prepared by vacuum evaporation of the elements on glass substrates coated with a $\mathrm{ZnO} / \mathrm{ZnO}: \mathrm{Al}$ bi-layer. Large grain size in the $\mathrm{Cu}(\mathrm{In}, \mathrm{Ga}) \mathrm{Se}_{2}$ layer was obtained with a modified three stage process while no additional source of sodium was used. As deposited devices showed a low fill factor due to a voltage dependent carrier collection. The fill factor and the open circuit voltage improved considerably upon light soaking. Efficiencies of up to $11.2 \%$ have been obtained. The capacitance voltage characteristics reveal a low effective carrier density in $\mathrm{Cu}(\mathrm{In}, \mathrm{Ga}) \mathrm{Se}_{2}$ of about $1 \cdot 10^{14} \mathrm{~cm}^{-3}$ for as-deposited cells. Light soaked cells show an increase in the carrier density by one order of magnitude which gives rise to a higher open circuit voltage. Additionally, measurements of the spectral response show an enhanced carrier collection under forward bias conditions.
\end{abstract}

\section{INTRODUCTION}

Thin film solar cells based on the chalcopyrite material $\mathrm{Cu}(\mathrm{In}, \mathrm{Ga}) \mathrm{Se}_{2}$ (CIGS) have approached efficiencies of $19 \%$ [1]. These results have been obtained with cells in the "substrate configuration" where the absorber layer is grown on Mo-coated soda lime glass; the solar cells are obtained by the subsequent deposition of a thin $\mathrm{CdS}$ layer and the front contact consisting of a $\mathrm{ZnO}: \mathrm{Al} / \mathrm{ZnO}$ bilayer. An alternate design is the "superstrate configuration," where the deposition sequence is reversed; thus, the absorber is grown on glass coated with the transparent front contact and finished by an evaporated metal back contact. Solar cells in this configuration offer the advantage of easy and reliable encapsulation, furthermore, they are important for the development of advanced tandem solar cells.

Recently an efficiency of $12.8 \%$ has been reported for superstrate solar cells prepared with coevaporated $\mathrm{Na}_{2} \mathrm{~S}$ as a source of $\mathrm{Na}$ doping in CIGS [2]. This contribution describes the development of superstrate solar cells without the use of an additional source or precursor of $\mathrm{Na}$. The performance of CIGS solar cells quite often improves upon light soaking or electrical biasing. The impact of light soaking is studied with measurements of the junction capacitance and the quantum efficiency.

\section{CELL PREPARATION}

The transparent front contact consists of an rf magnetron sputtered layer of $\mathrm{Al}$ doped $\mathrm{ZnO}$. The stability of the electrical conductivity against high temperatures, encountered during the subsequent CIGS deposition steps, was investigated with annealing experiments [3]. It was observed that the thermal stability of the conduction mechanism in $\mathrm{ZnO}: \mathrm{Al}$ critically depends on the sputtering conditions. A deposition process was developed where the electrical conductivity of the transparent front contact deteriorates only marginally; the resistivity of the $\mathrm{ZnO}: \mathrm{Al}$ layer in the finished device is estimated to be $1.8 \cdot 10^{-3} \Omega \mathrm{cm}$. Carrier density and mobility are $2.5 \cdot 10^{20} \mathrm{~cm}^{-3}$ and $20 \mathrm{~cm}^{2} / \mathrm{Vs}$, respectively. A $200 \mathrm{~nm}$ thick layer of undoped $\mathrm{ZnO}$ is used as a buffer between the front contact and the CIGS absorber layer.

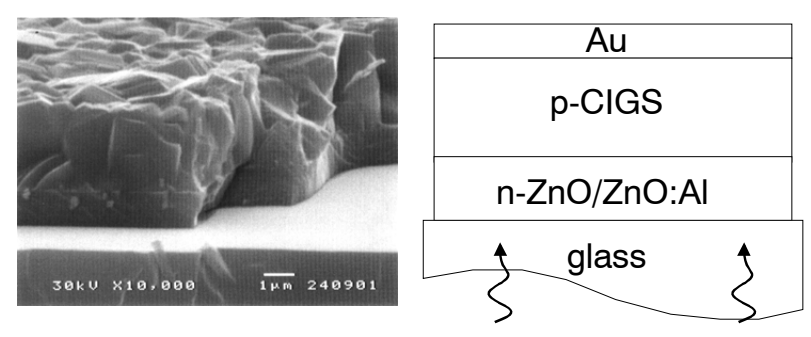

Fig. 1: Cross-section of a superstrate solar cell.

The absorber layer was grown by the co-evaporation of $\mathrm{Cu}, \mathrm{In}, \mathrm{Ga}$, and $\mathrm{Se}$ in vacuum. A modified three stage process was developed to obtain large grain size; first a layer of $(\mathrm{In}, \mathrm{Ga})_{2} \mathrm{Se}_{3}$ is deposited, followed by a Cu-rich growth regime, and finally the composition is adjusted under $\mathrm{Cu}$-poor conditions with an increased flux of $\mathrm{Ga}$. Investigations of the interface showed a strong accumulation of $\mathrm{Ga}$ at the interface to $\mathrm{ZnO}[4,5]$. The effect of this accumulation on the solar cell parameters is not clear. An increased Ga-content in the absorber layer close to the interface was proposed to result in a double graded 
band gap structure [2] which is also successfully employed in substrate solar cells $[6,7]$. However, a chemical analysis of the interface between $\mathrm{ZnO}$ and $\mathrm{CIGS}$ in superstrate solar cells revealed that $\mathrm{Ga}$ at the interface is bonded to oxygen rather than to selenium [5]. Thus, a barrier layer of insulating $\mathrm{Ga}_{2} \mathrm{O}_{3}$ is formed at the interface.

The diffusion of $\mathrm{Zn}$ from the $\mathrm{ZnO}$ layer into the absorber layer has been observed in superstrate solar cells [2]. The diffusion is not surprising, in case of substrate solar cells it was also found at much lower temperatures $[8,9]$. The electrical properties of CIGS can change because of $\mathrm{Zn}$ diffusion, e. g. $\mathrm{Zn}$ has been incorporated intentionally as n-type dopant into $\mathrm{Cu}(\mathrm{In}, \mathrm{Ga}) \mathrm{Se}_{2}$ [10] and $\mathrm{CuGaSe}_{2}$ [11] where it results in a conductivity type inversion and a buried homojunction.

In substrate type solar cells grown on soda lime glass, a considerable amount of $\mathrm{Na}$ diffuses from the glass through the Mo back contact into the absorber layer. Sodium has been reported to increase the grain size, passivate grain boundary effects and increase the effective acceptor concentration in CIGS [12]. All these effects collectively increase the efficiency of the solar cells. In the superstrate configuration, the diffusion of $\mathrm{Na}$ from the soda lime glass substrate is strongly inhibited by the $\mathrm{ZnO}: \mathrm{Al}$ front contact [4]. The addition of $\mathrm{Na}$ from co-evaporated $\mathrm{Na}_{2} \mathrm{Se}$ has been reported to increase the efficiency in superstrate cells from $4.9 \%$ to more than $10 \%[2,13]$.

\section{RESULTS AND DISCUSSION}



Fig. 2: Dark (circles) and light (squares) current voltage characteristics before (open) and after (full) light soaking. Also included is the $j-V$ curve of an $11.2 \%$ efficient superstrate solar cell (full triangles).

The $j-V$ characteristics of a typical superstrate solar cell before and after light soaking are presented in figure 2 . The as-deposited cells exhibit low efficiency and the light $j-V$ characteristics are often "S-shaped" which is also referred to as "double diode". However, substantial improvement in performance is observed after light soaking with a typical intensity corresponding to one sun. Usually, the short circuit current density changes only marginally while the open circuit voltage increases by about $200 \mathrm{mV}$, giving rise to an improved fill factor.

The characteristics in figure 2 exhibit a cross-over of dark and light $j-V$ curves and changes in the series resistance, indicating persistent photoconductivity and/or bias dependent carrier collection. The figure also includes the $j-V$ characteristic of an $11.2 \%$ efficient cell with an open circuit voltage of $530 \mathrm{mV}$, a short circuit current density of $34 \mathrm{~mA} / \mathrm{cm}^{2}$ and a fill factor of $64 \%$.

The dark $j-V$ measurements showed a decrease in the reverse saturation current density from $1.2 \cdot 10^{-7}$ to $6.3 \cdot 10^{-7} \mathrm{~mA} / \mathrm{cm}^{2}$ and an increase in the dark diode quality factor $\sim 1.2$ to $\sim 1.6$ due to light soaking. A straightforward explanation would assume a shift from predominant interface recombination to bulk recombination. However, deeper insight into the underlying transport mechanism would require temperature dependent measurements, but this has not been done yet.

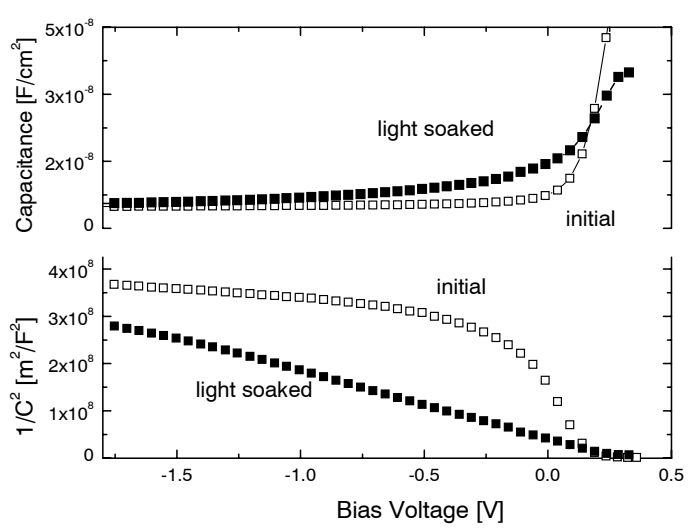

Fig. 3: Plots of the capacitance (above) and $1 / C^{2}$ (below) versus voltage, measured at $40 \mathrm{kHz}$. Open and full symbols denote the measurement before and after light soaking, respectively. The cell in the initial state shows the geometrical capacitance under reverse bias and a rapid increase under forward bias. After light soaking the linear relationship in the Mott-Schottky plot indicates uniform carrier density.

The impact of light soaking on the electrical properties and the quantum efficiency was investigated with the following measurement sequence: The $C-V$ characteristics of as-deposited cells were measured in dark, followed by measurements of dark and light $j-V$ characteristics. After that, the quantum efficiency of the cells was measured under working conditions (white light, intensity of one sun) at zero and under forward bias. This measurement 
sequence was repeated after light soaking under open circuit conditions and an intensity of one sun.

The variation of capacitance with voltage of a typical solar cell before and after light soaking is shown in figure 3 . The capacitance of about $6 \mathrm{nF} / \mathrm{cm}^{2}$ under reverse bias corresponds to the geometrical capacitance which indicates a totally depleted absorber layer. Towards forward bias the capacitance abruptly increases when the depletion region is swept rapidly through the whole absorber layer. This is due to a very low carrier concentration, the slope in the $1 / C^{2}$ plot around zero bias suggests a carrier density of approximately $1 \cdot 10^{14} \mathrm{~cm}^{-3}$.

After light soaking the capacitance is very much changed. The Mott-Schottky plot in figure 3 gives a reasonably straight line corresponding to a uniform carrier concentration of about $1.5 \cdot 10^{15} \mathrm{~cm}^{-3}$, which is one order of magnitude higher than the initial carrier density in CIGS before light soaking. This increase is due to a persistent saturation of trap states in the band gap CIGS and the corresponding release of trapped carriers [14].

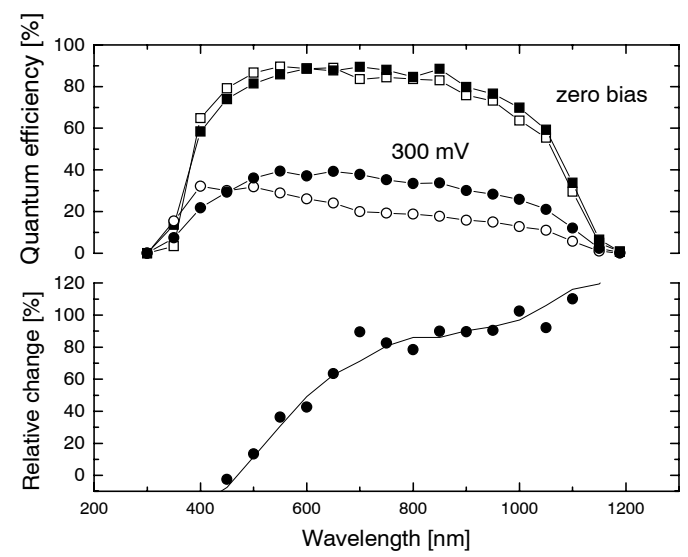

Fig. 4: Quantum efficiency (above) at two bias voltages before (open) and after (full symbols) light soaking. The measurements were performed with one sun white light bias. The lower plot illustrates the relative gain at $300 \mathrm{mV}$ forward bias.

The short circuit current density before and after light soaking changes only marginally from 32 to $34 \mathrm{~mA} / \mathrm{cm}^{2}$. This is consistent with the almost unchanged quantum efficiencies at zero bias, shown in figure 4. However, under a forward bias of $300 \mathrm{mV}$ the cell in the initial state shows a poor collection efficiently for carriers created by long wavelength photons. The lower plot in figure 4 illustrates that the quantum efficiency in this wavelength region is greatly enhanced after light soaking.

A possible explanation for this behaviour are the changes in space charge width after light soaking: Figure 3 shows that the capacitance of the light soaked cell under a forward bias of $300 \mathrm{mV}$ remains lower than the capacitance of the cell in the initial state. Thus, the space charge region under forward biased conditions remains wider and leads to a better collection of carriers generated by long wavelength photons deep in the bulk of CIGS.

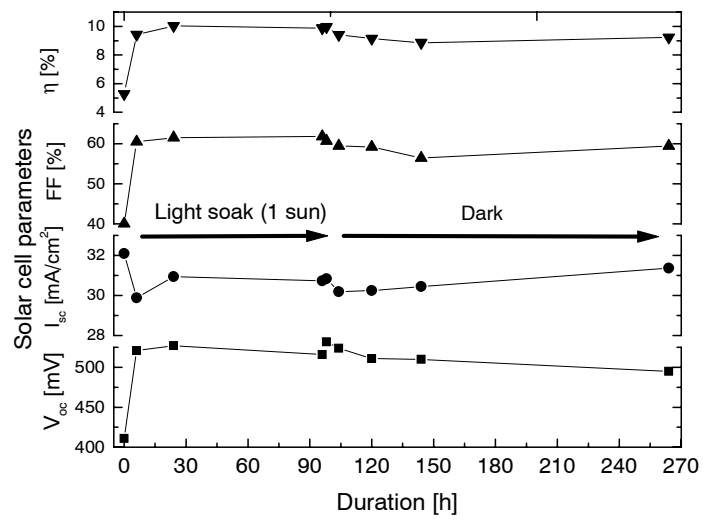

Fig. 5: Variations of the solar cell parameters during light soaking and subsequent storage in dark. The beneficial effect of light soaking is obtained after 10 to 15 minutes. When the cells are subsequently stored in dark the improvements are almost completely retained.

The time dependence of the light soaking effect is presented in figure 5 . The improvements in open circuit voltage and efficiency occur within 10 to 15 minutes, while the changes upon further illumination are only marginal. The behaviour in dark indicates a relaxation on very long time scales [15] or irreversible improvements like it was reported for electrically biased superstrate cells [2].

\section{CONCLUSIONS}

Superstrate solar cells with efficiencies of up to $11.2 \%$ were developed by co-evaporation. No additional source of $\mathrm{Na}$ was used. The effect of light soaking was investigated with measurements of the capacitance and the quantum efficiency. Light soaking increases the effective carrier density by one order of magnitude, presumably by the saturation of trap states. Measurements of the capacitance reveal that the space charge width under forward biased conditions is higher in light soaked cells. Thus carriers created by long wavelength photons are collected more efficiently by the electric field of the space charge region.

\section{ACKNOWLEDGEMENTS}

This investigation was supported by the Gebert Rüf Foundation and the Swiss Federal Office of Education and Science. 


\section{REFERENCES}

[1] M. A. Contreras, B. Egaas, K. Ramanathan, J. Hiltner, A. Swartslander, F. Hasoon, and R. Noufi, "Progress toward 20\% efficiency in $\mathrm{Cu}(\mathrm{In}, \mathrm{Ga}) \mathrm{Se}_{2}$ polycrystalline thin film solar cells," Progress in Photovoltaics: Research and Applications, vol. 7, pp. 311-316, 1999.

[2] T. Nakada and T. Mise, "High-efficiency superstrate type CIGS thin film solar cells with graded bandgap absorber layers." to be published in Proceedings $17^{\text {th }}$ European Photovoltaic Solar Energy Conference, Munich, 2001.

[3] F.-J. Haug, Z. Geller, H. Zogg, and A. N. Tiwari, "Influence of deposition conditions on the thermal stability of $\mathrm{ZnO}$ :Al films grown by rf magnetron sputtering," Journal of Vacuum Scienece and Technology $A$, vol. 19, no. 1, pp. 171-174, 2001.

[4] F.-J. Haug, M. Krejci, H. Zogg, A. N. Tiwari, M. Kirsch, and S. Siebentritt, "Characterization of $\mathrm{CuGaSe}_{2} / \mathrm{ZnO}$ for superstrate solar cells," Thin Solid Films, vol. 361-362, pp. 293-242, 2000.

[5] M. Terheggen, H. Heinrich, G. Kostorz, F.-J. Haug, $H$. Zogg, and A. N. Tiwari, "Diffusion of $\mathrm{Ga}$ in $\mathrm{Cu}(\mathrm{In}, \mathrm{Ga}) \mathrm{Se}_{2} / \mathrm{ZnO}$ superstrate solar cells and its impact on the photovoltaic properties," Thin Solid Films, vol. 403-404, pp. 212-215, 2002.

[6] M. A. Contreras, J. Tuttle, A. Gabor, A. Tennant, K. Ramanathan, S. Asher, A. Franz, J. Keane, L. Wang, J. Scofield, and R. Noufi, "High efficiency $\mathrm{Cu}(\mathrm{In}, \mathrm{Ga}) \mathrm{Se}_{2}$ based solar cells: Processing of novel absorber structures," in Proceedings $1^{\text {st }}$ World conference on Photovoltaic Solar Energy Convesion, Hawaii, pp. 68-75, IEEE, 1994.

[7] T. Dullweber, U. Rau, M. A. Contreras, R. Noufi, and H.-W. Schock, "Photogenreration and carrier recombination in graded gap $\mathrm{Cu}(\mathrm{In}, \mathrm{Ga}) \mathrm{Se}_{2}$ solar cells," IEEE Transactions on Electron Devices, vol. 47, no. 12 , pp. 2249-2254, 2000.

[8] T. Nakada, "Diffusion behaviour and microstructural properties of the CBD-ZnS/CIGS interface boundary," in MRS Symposium Proceedings, Spring Meet- ing, San Francisco, vol. 668, pp. H7.1.1-H7.1.9, Material Research Society, 2001.

[9] R. Hunger, P. Fons, K. Iwata, A. Yamada, K.Matsubara, S. Niki, K. Nakahara, and H. Takasu, "Observation of interdiffusion in $\mathrm{ZnO} / \mathrm{CuInSe}_{2}$ heterostructures and its effect on film properties," in MRS Symposium Proceedings, Spring Meeting, San Francisco, vol. 668, pp. H8.21.1-H8.21.6, Material Research Society, 2001.

[10] K. Ramanathan, H. Wiesner, S. Asher, D. Niles, R. N. Bhattacharya, J. Keane, M. A. Contreras, and R. Noufi, "High efficiency $\mathrm{Cu}(\mathrm{In}, \mathrm{Ga}) \mathrm{Se}_{2}$ thin film solar cells without intermediate buffer layers," in Proceedings $2^{\text {nd }}$ World Conference on Photovoltaic Solar Energy Conversion, Vienna, pp. 477-481, European Commission, 1998.

[11] J. H. Schön and E. Bucher, "Electrical properties of n-type CuGaSe ${ }_{2}$," Thin Solid Films, vol. 387, pp. 2325, 2001.

[12] M. Bodegård, K. Granath, and L. Stolt, "Growth of $\mathrm{Cu}(\mathrm{In}, \mathrm{Ga}) \mathrm{Se}_{2}$ thin films by coevaporation using alkaline precursors," Thin Solid Films, vol. 361-362, pp. 9-16, 2000.

[13] T. Nakada, T. Mise, T. Kume, and A. Kunoika, "Superstrate type $\mathrm{Cu}(\mathrm{In}, \mathrm{Ga}) \mathrm{Se}_{2}$ thin film solar cells with $\mathrm{ZnO}$ buffer layers - A novel approach to $10 \%$ efficiency," in Proceedings $2^{\text {nd }}$ World Conference Photovoltaic on Solar Energy Conversion, Vienna, pp. 413418, European Comission, 1998.

[14] F. Engelhardt, M. Schmidt, T. Meyer, O. Seifert, L. Bornemann, R. Harney, J. Parisi, W. Riedl, F. Karg, M. Schmidt, and U. Rau, "Reversible changes in the electrical tansport properties of $\mathrm{Cu}(\mathrm{In}, \mathrm{Ga}) \mathrm{Se}_{2}$ thin films and solar cells," in Proceedings $14^{\text {th }}$ European Photovoltaic Solar Energy Conference, Barcelona, pp. 1234-1237, H. S. Stephens and Associates, 1997.

[15] A. E. Delahoy, A. Ruppert, and M. A. Contreras, "Charging and discharging of defect states in CIGS/ZnO junctions," Thin Solid Films, vol. 361362, pp. 140-141, 2000. 